\title{
Acute Interstitial Nephritis with Polyclonal B Cell Infiltration and Development of Mantle Cell Lymphoma
}

\author{
Qiong Wu, Kiichiro Jinde, Hidetaka YANAGI, Masayuki EndOH and Hideto SAKAI
}

\begin{abstract}
A 69-year-old man with proteinuria, hematuria and abnormal renal and hepatic function developed acute renal failure. His clinical and laboratory examinations showed splenomegaly, edema, anemia and polyclonal hypergammaglobulinemia with high IgG levels. Renal biopsy showed interstitial nephritis with predominant $B$ cell and plasma cell infiltration without monoclonality. After corticosteroid treatment, the patient showed remission in clinical symptoms and laboratory findings. However, one year later, he developed mantle cell lymphoma (MCL) with typical lymphocyte markers of cyclin D1 and CD5. When evaluated retrospectively, this patient appeared to have multicentric Castleman's disease initially and developed MCL later. (Internal Medicine 41: 1158-1162, 2002)
\end{abstract}

Key words: acute renal failure, hypergammaglobulinemia, plasma cells, multicentric Castleman's disease

\section{Introduction}

Acute interstitial nephritis (AIN) is an important cause of acute renal failure (ARF), and can be induced by drugs, infection, immune-mediated diseases and glomerular diseases (14). AIN with no evident pathogenic cause is diagnosed as idiopathic AIN. The most common clinical presentations are skin rash, fever, eosinophilia and eosinophiluria, especially in drugassociated AIN. The typical findings in urinalysis include leucocytes, leucocyte casts and tubular protein $(1,2)$. Patients with AIN caused by systemic diseases may display clinical characteristics of the primary disease. Kidney size in AIN is normal or enlarged with an increased cortical echo level. Diagnosis of AIN is based mainly on the pathological characteristics of renal biopsy tissues (1). Here, we report a patient with AIN with many clinical abnormalities and numerous renal B cell and plasma cell infiltrations who developed mantle cell lymphoma one year later. These findings suggested that this patient might have had multicentric Castleman's disease although lymph node swelling was not observed at the beginning of the clinical course.

For editorial comment, see p 1086.

\section{Case Report}

A 69-year-old Japanese man was referred to our hospital in 2000 because of ARF. Three months before admission, he had a sore throat, but an otolaryngologic examination was unremarkable. He took a Chinese herbal medication for three weeks because of general fatigue. Two weeks previously, he felt severe fatigue and sought medical attention again. At this time, proteinuria, hematuria, abnormal renal function and hepatic dysfunction were disclosed. His renal function declined rapidly; the serum creatinine level rose from $4.5 \mathrm{mg} / \mathrm{dl}$ to $8.0 \mathrm{mg} /$ $\mathrm{dl}$ within four days.

On physical examination, his temperature was $36.4^{\circ} \mathrm{C}$, pulse $92 / \mathrm{min}$ and blood pressure $166 / 99 \mathrm{mmHg}$. No peripheral lymph node swelling was observed. The liver was palpated $1.5 \mathrm{~cm}$ below the costal margin, smoothly and painlessly. Lungs, heart and spleen were unremarkable. Extremities and neurological examination were normal. Otorhinolaryngologic and ophthalmologic examinations revealed no abnormalities. Chest and abdomen X-rays were normal. Abdominal ultrasonography showed that liver was normal and bilateral kidneys were enlarged with an increased echo level. Laboratory tests revealed normocytic, normochromic anemia (hemoglobin $10.1 \mathrm{~g} / \mathrm{dl}$ ), a white blood cell count of $4.0 \times 10^{3} / \mu 1$ with a lymphocytopenia $(21.2 \%)$ and a platelet count of $27.3 \times 10^{4} / \mu 1$. Serum total protein (TP) was $11.4 \mathrm{~g} / \mathrm{dl}$, albumin $3.2 \mathrm{~g} / \mathrm{dl}$, blood urea nitrogen (BUN) $50 \mathrm{mg} / \mathrm{dl}$, creatinine (Cr) $8.0 \mathrm{mg} / \mathrm{dl}$ and uric acid (UA) $9.9 \mathrm{mg} / \mathrm{dl}$. Liver function tests showed aspartate aminotransferase (AST) $88 \mathrm{IU} / l$, alanine aminotransferase (ALT) $112 \mathrm{IU} /$ $l$ and lactate dehydrogenase (LDH) 1,380 IU/l. Serum gammaglobulin level was increased to $55.0 \%$. A marked increase in levels of serum $\operatorname{IgG}(7,540 \mathrm{mg} / \mathrm{dl})$ and $\operatorname{IgM}(226 \mathrm{mg} /$ dl) was observed, although the serum IgA level was normal

From the Seventh Department of Internal Medicine, School of Medicine, Tokai University, Isehara

Received for publication June 6, 2002; Accepted for publication August 12, 2002

Reprint requests should be addressed to Dr. Qiong Wu, the Seventh Department of Internal Medicine, School of Medicine, Tokai University, 143 Shimokasuya, Isehara, Kanagawa 259-1193 


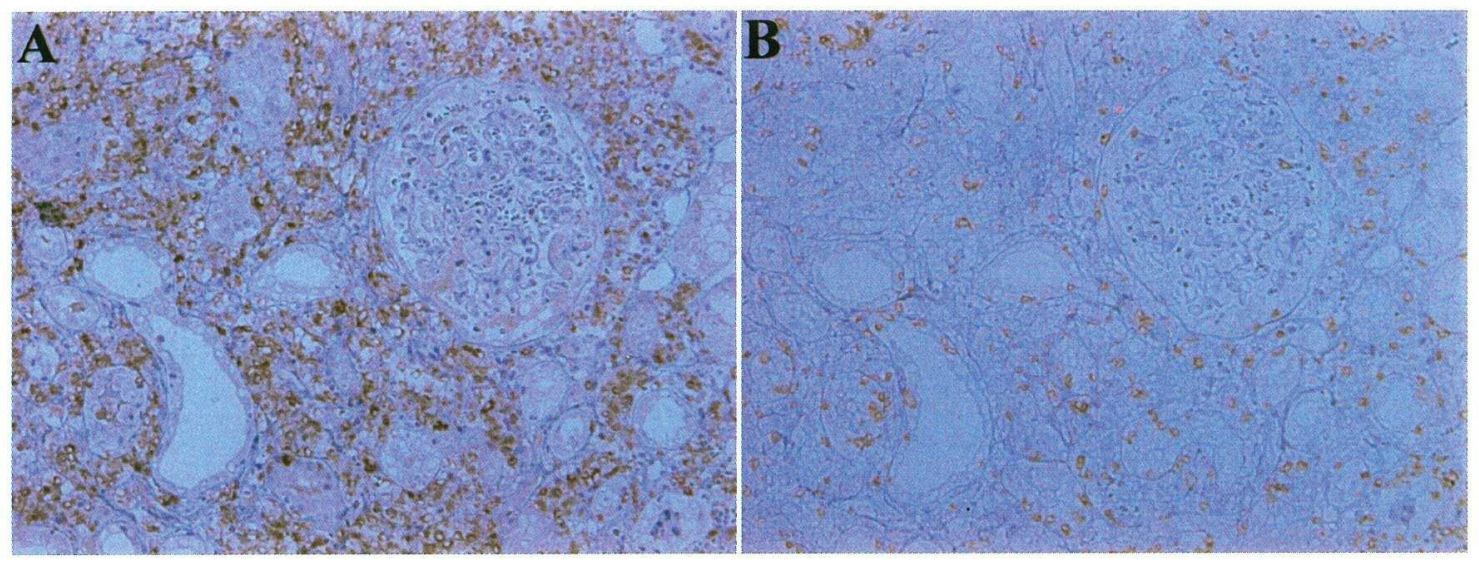

Figure 1. CD79a immunostaining (A) showed infiltration of a large number of CD79a positive $B$ cells in the renal interstitium. CD3 immunostaining $(B)$ showed that interstitial infiltrating CD3 positive T cells were not the main cell type in this case.

(143 mg/dl). Erythrocyte sedimentation rate was $133 \mathrm{~mm} / \mathrm{h}$ and C-reactive protein was $3.27 \mathrm{mg} / \mathrm{dl}$ (reference range $<0.3 \mathrm{mg}$ / dl). Urinalysis showed $24 \mathrm{~h}$ urine volume of $860 \mathrm{ml}$, urinary protein $1.3 \mathrm{~g} /$ day, glucose (+) and hematuria (3+), RBC 1-4/ HF, WBC $1-4 / \mathrm{HF}$ and hyaline casts (+). The endogenous creatinine clearance test showed $8.2 \mathrm{ml} / \mathrm{min}$ of GFR. The serum levels of sodium, potassium, chloride, calcium and phosphate were $119 \mathrm{mEq} / l, 3.5 \mathrm{mEq} / l, 94 \mathrm{mEq} / l, 7.3 \mathrm{mg} / \mathrm{dl}$ and $4.9 \mathrm{mg} /$ $\mathrm{dl}$, respectively. Tests for HBsAg, HCV antibody, anti-nuclear antibody, lupus erythematosus (LE) cell, anti-ds-DNA, antiSSA, anti-SSB, MPO-ANCA, PR3-ANCA and rheumatoid factor were all negative. Bone marrow aspiration performed because of suspected multiple myeloma showed normocellular marrow with a slight increase of mature plasma cells (3.4\%). No monoclonality of plasma cells was observed in immunohistochemical studies. Bone marrow findings with a negative Bence-Jones protein test ruled out the diagnosis of multiple myeloma. In order to determine the reason for ARF, open renal biopsy was performed. No apparent glomerular abnormality was discerned except for four out of 50 hyalinized glomeruli. The stroma revealed marked and dense infiltration of lymphoid cells and mature plasma cells without formation of lymphoid follicles. Characteristically, lymphoid cells (small and mediumsized centrocyte-like cells) infiltrated among the tubular epithelial cells, resulting in the formation of lymphoepithelial lesions. The majority of infiltrating cells were immunoreactive for the B-cell marker, CD79a (Fig. 1A) and partially for CD20. Small T-lymphocytes were observed sporadically (Fig. 1B). The plasma cells in the interstitium showed predominant IgG production (Fig. 2), but no monoclonality was identified for the light chains. The patient was then diagnosed as having acute interstitial nephritis with predominant B lymphocyte infiltration. Corticosteroid therapy was initiated using $40 \mathrm{mg} /$ day of prednisolone. The patient showed good response to steroid therapy and serum levels of IgG, TP, BUN, Cr, UA, AST, ALT

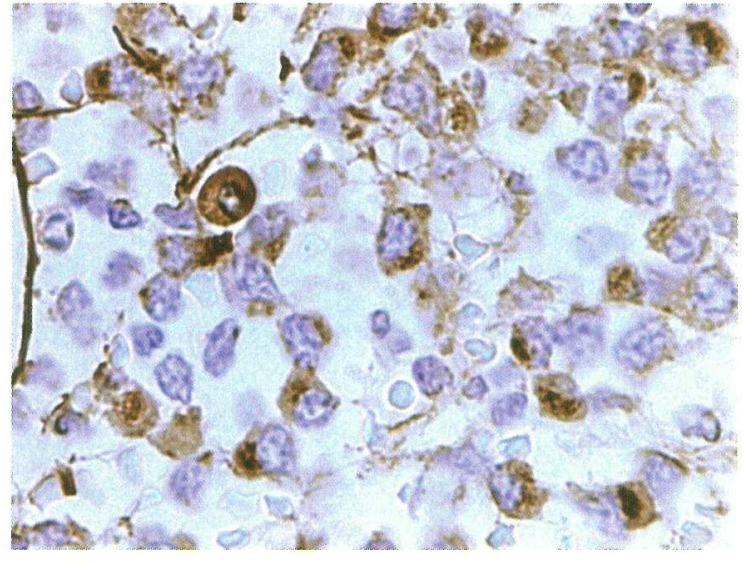

Figure 2. IgG immunostaining revealed many plasma cells in the renal interstitium, which were producing IgG immunoglobulin.

and LDH were all decreased. Serum Cr returned to the normal level and remained at $1.0 \mathrm{mg} / \mathrm{dl}$.

One year after treatment of AIN, the patient again felt fatigue with weight loss, then developed dyspnea and peripheral lymph node swelling. Chest and abdomen CT scans showed enlargement of the hilar, mediastinal, left axillar and inguinal lymph nodes. Flow cytometry of the lymph node indicated cellular characteristics of CD19+, CD20+, CD22+, CD25+, CD5+, HLA-DR + with $\lambda$ light chain monoclonality. Together with the histopathological findings of biopsy tissues from skin and bone marrow, a diagnosis of mantle cell lymphoma (MCL) was determined. The test for human T cell lymphoma virus (HTLV-1) was negative. The in situ hybridization test for Epstein-Barr virus showed negative results in the skin, lymph node taken at the second admission and kidney tissue taken at the first ad- 
Cyclin D1
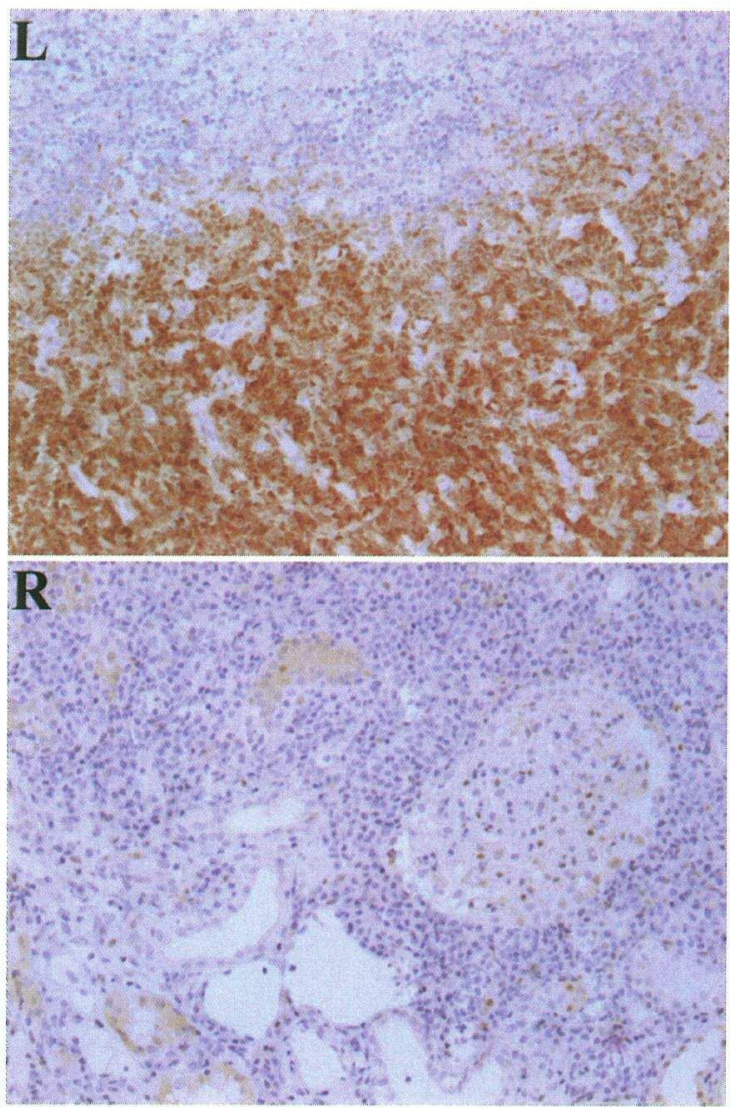

CD5

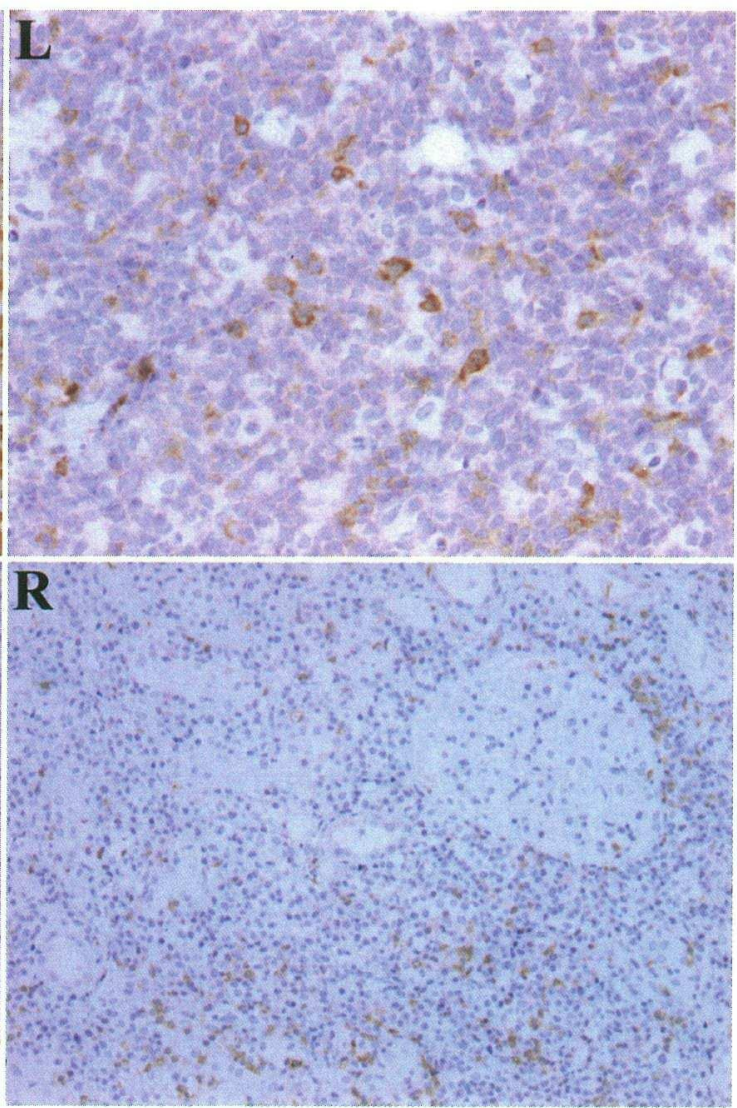

Figure 3. Cyclin D1 and CD5 immunostaining. Strong cyclin D1 and CD5 expression was observed in a lymph node (L), while almost no cyclin D1 and CD5 expression was observed in the renal tissue (R).

mission. Serum IL-2R level was significantly increased to $17,500 \mathrm{U} / \mathrm{ml}$ (reference range $220-530 \mathrm{U} / \mathrm{ml}$ ). The patient died of serious pulmonary infection one month after starting radiotherapy and chemotherapy.

Immunohistochemical staining of renal tissue, taken at the initial admission, for cyclin D1 and CD5 was negative for cyclin D1 and only slightly positive for CD5. But, immunohistochemical lymph node staining, taken at the second admission, was strongly positive for cyclin D1 and CD5 (Fig. 3). These findings suggested that MCL developed after recovery from AIN in this patient.

\section{Discussion}

We diagnosed our patient as having AIN because his renal tissue showed that almost all glomeruli were normal in appearance except for four out of fifty that were hyalinized, while infiltration of lymphoid cells and mature plasma cells in the tubulointerstitium was marked with occasional findings of tubulitis. The most common pathogenic factor in AIN is con- sidered to be drugs $(1,2)$. Our patient had been using a Chinese herb but no other drugs before he developed ARF. Some Chinese herbs were recently reported to pose a risk of interstitial nephritis and some patients using them developed ARF (57). The main component of the Chinese herb our patient used was Ginseng, which has not been reported as a cause of AIN. A lymphocyte stimulation test was performed on this herb with negative results. Therefore, we ruled out the herb as a cause of AIN in this case. Infection is the second common cause of AIN. Streptococcal tonsillitis can cause AIN with ARF (4). Our patient had a sore throat three months before development of ARF. However, post-infectious AIN was ruled out because he did not develop tonsillitis and the otolaryngologic examination was normal at that time. AIN caused by systemic diseases such as Sjögren's syndrome, systemic lupus erythematosus (SLE) and sarcoidosis is not rare. Our patient did not have these systemic diseases based on his clinical profile and laboratory results. We could not find the cause of AIN in this patient.

The interesting point in this case was that the interstitial infiltrating cells were different from those in most reports, in 
which the interstitial infiltrates consisted mainly of $\mathrm{T}$ cells, followed by monocytes and B cells in patients with AIN associated with nonsteroidal anti-inflammatory agents and betalactam antibiotics $(1-3,8)$, with tubulointerstitial nephritisuveitis syndrome $(1,9)$ and with idiopathic $\operatorname{AIN}(1,10)$. Plasma cells and eosinophils were relatively rare $(2,8)$ although in rare cases eosinophils were the main infiltrating cells in druginduced AIN (11). In the present case, the interstitial infiltrating cells were mostly CD79a positive B cells and mature plasma cells with predominant IgG production. CD3 positive T lymphocyte infiltration was observed much less frequently.

This patient developed MCL one year after AIN. To determine if lymphoma had been present when AIN appeared, we studied cyclin D1 and CD5 expression, characteristic markers of MCL $(12,13)$, in a lymph node and renal tissue immunohistochemically. The renal tissue showed no cyclin D1 positive and only a few CD5 positive cells (T cells), but the lymph node was strongly positive for cyclin D1 and CD5. These findings suggested that this patient had not developed MCL at the time of AIN.

Castleman's disease, also called angiofollicular lymph node hyperplasia, is a rare atypical lymphoproliferative disorder of unknown cause. Diagnosis is based on histologic characteristics of lymph nodes. Castleman's disease can be divided into three histologic subtypes (hyaline vascular type, plasma cell type and mixed type) (14) and two clinical types: localized Castleman's disease and multicentric Castleman's disease (15). Localized Castleman's disease usually occurs in young patients and presents with masses mainly in the abdomen and mediastinum (16-18). Most patients with localized forms have no systemic symptoms $(15,16,18,19)$. In the contrast, patients with multicentric forms are older and have systemic symptoms such as fatigue, fever, weight loss, night sweats, nausea, and physical abnormalities such as splenomegaly, hepatomegaly, edema, polyneuropathy and skin rash $(15,16,19-23)$, and laboratory abnormalities such as anemia, hypergammaglobulinemia, elevated IL-6, hypoalbuminemia, elevated erythrocyte sedimentation rate, proteinuria, elevated creatinine, elevated liver function tests and thrombocytopenia (16, 19-23). In this case, general fatigue before ARF, hepatomegaly and edema (after correction of dehydration) were observed. Except for thrombocytopenia and untested IL-6, all of the above laboratory abnormalities were found. The serum gammaglobulin in our patient was considered polyclonal according to immunoelectrophoresis and the renal immunohistochemical examination. Patients with multicentric Castleman's disease are at an increased risk of developing Kaposi's sarcoma, Hodgkin's disease and nonHodgkin's lymphoma (NHL) (20, 21, 23-28). Larroche et al (24) found that NHL, especially MCL, was more often associated with multicentric Castleman's disease. The present patient developed MCL in the terminal stage. Diagnosis of multicentric Castleman's disease is based on histological features of lymph nodes. Our patient did not display lymph node swelling in the initial admission with ARF due to AIN, and we were unable to diagnose multicentric Castleman's disease initially. The infiltrating cells in renal tissue of our patient produced polyclonal IgG. This is quite similar to the clonality present in the majority of Castleman's disease cases, in which the accumulating lymphoid cells are mainly polyclonal (28). Interstitial nephritis has been described in two patients with multicentric Castleman's disease. The renal infiltrating cells were T lymphocytes and plasma cells in one case (29) and mainly IgG produced polyclonal plasma cells with some lymphocytes in the other (30). Our case showed the similar features. In these two cases, the same histologic changes were found in different involved tissues such as in lung and in kidney in the first case and in kidney and in lymph nodes in the second case. Taken together, the present patient had most of the characteristics of multicentric Castleman's disease during the clinical course and he developed a B cell lymphoma in the terminal stage.

In this patient acute interstitial nephritis with predominant B cell infiltration appeared to be a prelymphoma state, with a strong possibility of multicentric Castleman's disease before development of definite MCL.

\section{References}

1) Michel DM, Kelly CJ. Acute interstitial nephritis. Am J Soc Nephrol 9: 506-515, 1998.

2) Koren G. The nephrotoxic potential of drugs and chemicals. Pharmacological basis and clinical relevance. Med Toxicol Adverse Drug Exp 4: 59-72, 1989.

3) D'Agati VD, Theise ND, Pirani CL, Knowles DM, Appel GB. Interstitial nephritis related to nonsteroidal anti-inflammatory agents and beta-lactam antibiotics: a comparative study of the interstitial infiltrates using monoclonal antibodies. Mod Pathol 2: 390-396, 1989.

4) Dharmarajan TS, Yoo J, Russell RO, Boateng YA. Acute post streptococcal interstitial nephritis in an adult and review of the literature. Int Urol Nephrol 31: 145-148, 1999.

5) Li X, Yang L, Yu Y. An analysis of the clinical and pathological characteristics of mu-tong (a Chinese herb) induced tubulointerstitial nephropathy. Zhonghua Nei Ke Za Zhi 40: 681-687, 2001 (in Chinese, Abstract in English).

6) Chen W, Chen Y, Li A. The clinical and pathological manifestations of aristolochic acid nephropathy - the report of 58 cases. Zhonghua Yi Xue Za Zhi 81: 1101-1105, 2001 (in Chinese. Abstract in English).

7) Nishimagi E, Kawaguchi Y, Terai C, Kajiyama H, Hara M, Kamatani N. Progressive interstitial renal fibrosis due to Chinese herbs in a patient with calcinosis Raynaud esophageal sclerodactyly telangiectasia (CREST) syndrome. Intern Med 40: 1059-1063, 2001.

8) Olsen TS, Wassef NF, Olsen HS, Hansen HE. Ultrastructure of the kidney in acute interstitial nephritis. Ultrastruct Pathol 10: 1-16, 1986.

9) Yoshioka K, Takemura T, Kanasaki M, Akano N, Maki S. Acute interstitial nephritis and uveitis syndrome: activated immune cell infiltration in the kidney. Pediatr Nephrol 5: 232-234, 1991.

10) Pamukcu R, Moorthy V, Singer JR, Hong R, Simpson DP. Idiopathic acute interstitial nephritis: characterization of the infiltrating cells in the renal interstitium as T helper lymphocytes. Am J Kidney Dis 4: 24-29, 1984.

11) Makino $H$, Haranoto $T$, Sasaki $T$, et al. Massive eosinophilic infiltration in a patient with the nephritic syndrome and drug-induced interstitial nephritis. Am J Kidney Dis 26: 62-67, 1995.

12) Harris NL, Jaffe E, Stein H, et al. A revised European-American classification of lymphoid neoplasms, a proposal from the International Lymphoma Study Group. Blood 84: 1361-1392, 1994.

13) Swerdlow SH, Williams ME. From centrocytic to mantle cell lymphoma: a clinicopathologic and molecular review of 3 decades. Hum Pathol 33: 7-20, 2002.

14) Keller AR, Hochholzer L, Castleman B. Hyaline-vascular and plasmacell types of giant lymph node hyperplasia of the mediastinum and other 


\section{Wu et al}

locations. Cancer 29: 670-683, 1972.

15) Herrada J, Cabanillas F, Rice L, Manning J, Pugh W. The clinical behavior of localized and multicentric Castleman disease. Ann Intern Med 128: 657-662, 1998.

16) Bowne WB, Lewis JJ, Filippa DA, et al. The management of unicentric and multicentric Castleman's disease. A report of 16 cases and a review of the literature. Cancer 85: 706-717, 1999.

17) Frizzera G. Castleman's disease and related disorders. Semin Diagn Pathol 5: 346-364, 1988.

18) Vasef M, Katzin WE, Mendelsohn G, Reydman M. Report of a case of localized Castleman's disease with progression to malignant lymphoma. Am J Clin Pathol 98: 633-666, 1992.

19) Maslovsky I, Uriev L, Lugassy G. The heterogeneity of Castleman disease: report of five cases and review of the literature. Am J Med Sci 320: 292-295, 2000.

20) Lajoie G, Kumar S, Min KW, Silva FG. Renal thrombotic microangiopathy associated with multicentric Castleman's disease. Report of two cases. Am J Surg Pathol 19: 1021-1028, 1995.

21) Weisenburger DD, Nathwani BN, Winberg CD, Rappaport H. Multicentric angiofollicular lymph node hyperplasia, a clinicopathologic study of 16 cases. Hum Pathol 16: 162-172, 1985.

22) Lee M, Hirokawa M, Matuoka S, et al. Multicentric Castleman's disease with an increased serum level of macrophage colony-stimulating factor. Am J Hematol 54: 321-323, 1997.
23) Kessler E. Multicentric giant lymph node hyperplasia. A report of seven cases. Cancer 56: 2446-2451, 1985.

24) Larroche C, Cacoub P, Soulier J, et al. Castleman's disease and lymphoma: report of eight cases in HIV-negative patients and literature review. Am J Hematol 69: 119-126, 2002.

25) Codish S, Abu-Shakra M, Ariad S, et al. Manifestations of three HHV-8related diseases in an HIV-negative patient: immunoblastic variant multicentric Castleman's disease, primary effusion lymphoma, and Kaposi's sarcoma. Am J Hematol 65: 310-314, 2000.

26) De Rosa G, Barra E, Guarino M, Gentile R. Multicentric Castleman's disease in association with Kaposi's sarcoma. Appl Pathol 7: 105-110, 1989.

27) Dickson D, Ben-Ezra JM, Reed J, Flax H, Janis R. Multicentric giant lymph node hyperplasia, Kaposi's sarcoma, and lymphoma. Arch Pathol Lab Med 109: 1013-1018, 1985.

28) Soulier J, Grollet L, Oksenhendler E, et al. Molecular analysis of clonality in Castleman's disease. Blood 86: 1131-1138, 1995.

29) Sato T, Wakabayashi Y, Hirasawa A, Tashiro Y, Nishikawa T, Chiba S. Multicentric Castleman's disease accompanied with both lymphoid interstitial pneumonia and interstitial nephritis. Rinsho Ketsueki 35: 13221328, 1994 (in Japanese, Abstract in English).

30) Frokjaer Thomsen O, Ladefoged J. Castleman's disease with renal infiltration by polyclonal plasma cells. Clin Nephrol 49: 328-330, 1998. 